\title{
Community Radio Stations Messages And Promotion Of Family Planning Methods In Kibra Constituency, Nairobi County, Kenya
}

\author{
Justina Kathambi * and Professor Hellen Mberia ${ }^{* *}$ \\ * Master's Degree Scholar at Jomo Kenyatta University of Agriculture and Technology, Kenya \\ ** Lecturer at the Scholl of Communication and development Studies at Jomo Kenyatta University and Technology, Kenya. \\ DOI: 10.29322/IJSRP.11.09.2021.p11745 \\ http://dx.doi.org/10.29322/IJSRP.11.09.2021.p11745
}

\begin{abstract}
This study sought to determine the influence of community radio stations messages and promotion of family planning methods in Kibra constituency, Nairobi county, Kenya. The study identified the community radio stations message components aired in form of discussions, campaign and debates and their promotion of family planning methods. Among the three message components, debates emerged as an underutilized component when compared to discussions and campaigns. The study found out that there is a substantial evidence that the in effectiveness and ineffectiveness of family planning methods use and utilization of available free governmental services was hampered by messages aired in radios. However, the study highlighted radio discussions as the main contributing element to media content seconded by campaigns. The study established that most of the respondents were having below college education which was an indicator that poverty levels were likely to continue hitting the slum areas as poverty and low access to education are highly correlated. A high percentage of the women who had sex reported to have heard from radios about the favorable method to be used and also used their first family planning measures, which is use of a condom at the age of 13 to 19 years.
\end{abstract}

\section{INTRODUCTION}

$\mathrm{C}$ ommunity radio is definitely an inexpensive medium that the Government of Kenya through the CCK may want to promote by offering subsidized FM airwave licences and discounted annual fees to registered NGOs, churches, schools and other public institutions. This is with a view to propagating its policies including increasing awareness of critical issues like civic education, HIV/Aids and environmental conservation (Goodman, et.al, 2016). According to world population reports, radio is the primary link between the world and the people and what people listen to from the radio influences largely what they talk about, think and behave. The role of radio, together with press, television, billboards, print materials, and personal communication, depends on goals, costs, access to broadcasting, and how well radio reaches intended audiences. But radio is always an attractive medium because almost everyone listens to radio; radio has an attentiongetting immediacy that makes it convincing; and radio programing is flexible. If family planning communicators learn how to use radio better, radio can play a bigger role in child spacing, and child survival.

Producing persuasive family planning materials for radio requires good quality in both content and presentation. Mass media communication is a process consisting of initial research and analysis, design, message development, pre-testing, implementation, and evaluation. Audience research and constant feedback are essential throughout. Family planning organizations can develop useful radio projects with big or small budgets.

\subsection{SATEMENT OF THE PROBLEM}

Messages aired through Community radio influence the promotion of family planning methods among women in the society (WHO, 2018). However, the level of awareness on the family planning methods is still slow. Therefore, in order to enhance the uptake of family planning services as a bold step towards meeting the challenges envisaged in the Kenya's Vision 2030 and the realization of the Sustainable Development Goals (SDGs), there is need to ascertain whether the content aired by the Community radio is in the right form. It is not only in the right form but also to know which way of packaging is more efficient. This is because some of the words that relate to family planning are culturally considered abominable and there is a big impact of the sheng in most urban centers especially in ghetto. It would also be important to understand whether the messages get to the right people in the right form. According to Schottenfeld, 2013 studies in developing countries have shown that women in slum areas are reluctant in adopting family planning methods as the number of child birth is still high. KDHS (2008-09) reports that slightly less than half of currently married Kenyan women (46 percent) are currently using some method of contraception. It is therefore important to note that information in regard behavior change is essential for communities to realize the importance of utilizing family planning methods to reduce the number of children. It is against this backdrop that the current study was conducted.

\subsection{OBJECTIVES}

The study sought to establish the influence of radio stations messages on promotion of family planning methods in Kibra constituency Nairobi county. In general, the study's main goal was to determine the influence of community radio stations messages components in form of debates, discussions and campaigns on 
promotion of family planning methods in Kibra constituency, Nairobi county.

\section{THEORITICAL BACKGROUND AND LITERATURE REVIEW}

This section highlights the literature review and the theories informing the objectives of the study.

\subsection{THEORITICAL BACKGROUND}

This study was based on the diffusion theory and uses and gratification model. Makowsky, et al (2013), notes that in a changing society, there is a constant flow of innovations. Some are invested by members of society others are borrowed from other groups. He concludes that this theory is crucial in study of mass communication because media are often largely responsible for bringing new items to attention of people who eventually adopt them.

The diffusion process is concerned with the final stage of adoption or rejection of an innovation. In this research project, the researcher sought to investigate use of radio (which is an innovation itself), and diffusion of modem family planning methods. The processes of spread and adoption of both the radio and the contraceptives follows closely on the diffusion of innovations theory. It is evident that radio as a technological advancement has been well adopted in Kibra constituency and that it is this goodwill that family planning policy makers can capitalize on it in spreading ideas about family planning in Kibra constituency.

This study aimed at demonstrating that radio and its audience have inseparable relationships by using the uses and gratification theory. According to Tanta (2014), the gratification theory addresses the desire to meet a certain need by users who find the find the content useful. That when communicators effectively use radio in family planning communication and exploit the benefits of radio in communities, this could result to increased demand for uptake of family planning services. Consequently, the information as provided by respondents would help the radio programmers and family planning communication officers to identify which programs and reasons motivate Kibra women to tune to radio and are of great interest to listeners and therefore enjoy wide listenership in the county. Such programs can then be incorporated into family planning campaigns, discussions, debates and telephone call in programs to sensitize Kibra women while at same time entertaining them.

\subsection{LITERATURE REVIEW}

Fraser and Estrada (2001) explain the functions of a community radio as a reflection and promotion of local identity, culture and character as the most central. This is achieved through provision of programming that is particular to its community identity and character through the local content that is aired by the station. A community radio should air diverse voices and opinions. Encouraging of dialogue is an issue critical in community radio broadcasting. Since the radio station is open to all sections of people in the community, it offers them a good opportunity to air their diverse views on any issue of interest. Through such dialogue local listeners can participate in democratic process.

According to Wabwire, (2013) marginalized communities have typically adopted community radio as a tool for highlighting their fundamental rights. Siemering, (1998) states that in Latin American countries, community radio, otherwise known as peoples' radio, became the voice of the poor and the voiceless, the landless peasants, the urban hut dwellers, the impoverished indigenous nations and the trade unions. Given the kind of populations to whom they are targeted, community radios have also been used as tools for development. Such communities have used radio to raise and address issues exceptional to their experiences. In particular, minority groups marginalized by the mainstream media find solace in the capabilities of community radio.

According to Fraser (2001), a community radio performs the function of providing an independent platform for interactive discussion about matters of importance to the community. Fraser (2001), further argues that for development to take place there has to be a collective will on the part of the community to improve its welfare, however he insists that, that was only possible through internal discussions within the community about its situation, the causes and possible action for improvement. Fraser summarizes a community radio as a platform to give a voice to the voiceless.

\section{METHODOLOGY}

The research used the quantitative approach which was appropriate for the study since the study sought to establish if family planning messages are transmitted by Community radio stations in Kibra constituency. This was a mixed method study of how Community radio stations in Kibra constituency are promoting family planning methods. A questionnaire was used to find out how Kibra constituency people use community radio stations to make decisions on use and impact of family planning. They were also used to ascertain what effects community radio stations have on family planning methods issues on women.

\section{CONCLUSION}

The study concluded the following; Most of the respondents were having below college education which was an indicator that poverty levels were likely to continue hitting the slum areas as poverty and low access to education are highly correlated. Majority of the respondents are believers and faith and rigidity are at times highly correlated as some studies indicated. The above implies that since most households are single, family planning may not have taken many routes in the communities living in Kibra subcounty. This singlehood has a high correlation with the high level of poverty. All the observations indicated that there was no autocorrelation as indicated by the Durbin Watson Results. None of the observations was geared towards positive autocorrelation or negative autocorrelation as indicated. The findings observed implied that only community radio stations had a linear or predictable relationship with the dependent variable.

The other observations showed that the relationship was quite in order and thus stable to run a test analysis. It can be drawn that there was no collinearity between the radio programs debates, campaigns, and discussion of the community radio stations in Kibra constituency as most showed low collinearity values of 1 . Therefore, the study found out that there is a substantial evidence 
that the in effectiveness and ineffectiveness of family planning methods use and utilization of available free governmental services was hampered by messages aired in radios. From the data analyzed the findings showed that debates are not utilized which according to Shih et. al, (2008) they are mass media components that help draw a line for the audience to determine what suits them. The study also concludes that the radio hosts only focus on the trending topics and assume the key social factor that include child bearing which also has more people listening. Therefore, most people felt that there is a need to have adequate time allocation of such social issues on radio productions to foster more engagements. Respondents seemed to strongly agree with the fact that they get family planning messages through radio stations but shed light on the program producers to generate content that will help them make sober decisions based on one's capability.

\section{RECOMMENDATIONS}

The study recommended the following;

1. There is a positive relationship between radio station discussions and the promotion of family planning methods. Therefore, radio stations messages inform of discussions should be encourage to address issues pertaining family planning methods as part of the media role in disseminating information.

2. Policy holders should ensure that universities include more of the radio messages components that is through discussions, debates, and campaigns in their curriculum to ensure that radio hosts understand and utilize them well.

3. They should ensure that radio stations program producers consider addressing child bearing and family planning which is a key determining factor to one'slifetimeachievement.

4. A study should be conducted to find out how other mediums of communication influence behavior to help the government and the industry stakeholders to understand the strength of each message component.

5. Agenda setting should also be one of the key focus by scholars to look at how radio stations message packaging have been able to reach many people.

6. An evaluation of radio messages performance will help establish a potential and diverse viewpoint on the radio programs role in promotion of family planning methods.
7. On campaigns, NGOs should sponsor most of them based on the locality situation that will ensure people from the slums benefit from listening to radio stations.

\section{REFERENCES}

[1] Fraser C. and Estrada S.R. (2001). Community Radio handbook, UNESCO.

[2] Sports. Series J: Family Planning Programs (46): 1-35.

[3] Goodman, M. L., Selwyn, B. J., Morgan, R. O., Lloyd, L. E., Mwongera, M., Gitari, S., \& Keiser, P. H. (2016). Sexual behavior among young carers in the context of a Kenyan empowerment program combining cash-transfer, psychosocial support, and entrepreneurship. The Journal of Sex Research, 53(3), 331-345.

[4] Kenya Demographic Health Surveys (2008): Publication by the Kenya National Bureau of Statistics; Government Press, Nairobi.

[5] Makowsky, M. J., Guirguis, L. M., Hughes, C. A., Sadowski, C. A., \& Yuksel, N. (2013). Factors influencing pharmacists' adoption of prescribing: qualitative application of the diffusion of innovations theory. Implementation Science, 8(1). https://doi.org/10.1186/1748-5908-8-109

[6] Schottenfeld, D., Beebe-Dimmer, J. L., Buffler, P. A., \& Omenn, G. S. (2013). Current perspective on the global and United States cancer burden attributable to lifestyle and environmental risk factors. Annual review of public health, 34 .

[7] Siemering, W. (1998). William H. Siemering. Www.macfound.org. https://www.macfound.org/fellows/class-of-1993/william-h-siemering

[8] Shih ,T., Wijaya, R., \& Brossard, D.(2008). Media Coverage of Public Health Epidemics: Linking Framing and Issue Attention Cycle Toward an Integrated Theory of Print News Coverage of Epidemics. Mass Communication and Society, 11(2), 141-160.

[9] Wabwire, (2013). Sri Lanka's Kothmale Community Radio internet project. Retrieved January 28, 2007, from from http://poverty2.forumone.com/library/view/14651/

[10] World Health Organization (2018). Family planning methods: a public priority. Geneva: World Health Organization.

\section{AUTHORS}

First Author - Justina Kathambi, Masters Degree Candidate at Jomo Kenyatta University of Agriculture and Technology, Kenya Second Author - Professor Hellen K. Mberia is a Lecturer at the School of Communication and Development Studies at Jomo Kenyatta University of Agriculture and Technology, Kenya 